\title{
Editorial
}

\section{Locating clinic and ourselves within it}

Elaine Hall

Northumbria University, UK

Elaine.Hall@northumbria.ac.uk

In this edition we return to a key theme for this journal, mapping our clinical practice. Why is this process of mapping so important? I'd like to advance the argument that mapping in academic practice can be seen as a mindfulness technique, enabling us to evaluate the past, to dream of and plan for the future and most crucially to experience the present. This awareness of where we are now allows us to be engaged actors, rather than the cranky passive consumers that John Brehm describes:

... we'd still be waiting for the next thing to happen in Heaven, the next violin concerto or cotton candy festival or breathtaking vista to open beneath our feet, and thinking this place isn't quite what it's cracked up to be, and why in hell does everybody want to get here? We'd still be waiting for someone else to come and make us happy, staring through whatever's in front of us, cursing the light that never seems to change. 
This time we use a number of lenses: geographically, in terms of partnerships and pedagogy and also theoretically.

Adrian Evans and Ross Hyams' paper is particularly useful as an aid to future travel, since they give us the benefit of a range of perspectives: they provide a large scale map of externship practice in Australian clinical legal education, then swoop down to street level to give a case example of externship partnerships at Monash University before gaining reflective distance on externships as a phenomenon, offering an analysis of strengths and weaknesses.

Clelia Bartoli from Palermo reports from the field not just on the development of separate clinics across Italy but also on the sense that a movement is growing, suggesting that like-minded (she specifies philosophical and speculative as leading characteristics) law teachers have identified clinic as a vehicle for a larger social and pedagogic project.

Elaine Campbell's reflexive exploration of her practice as a clinical supervisor takes us further down this road, focusing on the internal tensions for the supervisor of ceding power to the student and the uncertainty that comes from disrupting the relational expectations. The eventual rewards are significant for (most) students and this is a telling account of a particular voyage.

Finally, Rachel Lofthouse reviews Learning in Landscapes of Practice, a book that helps us to locate our work theoretically but not in a scary way! Rather, she found it "a 
genuine invitation into other lives and ideas... thought-provoking, evocative and illustrative". If as Clelia Bartoli suggests, we are inherently philosophical, we would do well to engage with the ideas in this book so as to be able to link our work into wider networks, across disciplines and into different maps.

As usual, before signing off I would like to draw your attention to a series of upcoming events in the CLE world. Late this year, ENCLE will host their $3^{\text {rd }}$ Conference: '(R)evolution of clinics in Europe'. It will be held on 26 and 27 October 2015 at the Faculty of Law, ELTE University, Budapest. The call for papers closed on $15^{\text {th }}$ July and it promises to be a vibrant and exciting meeting, please see the ENCLE site for updates $\underline{w w w . e n c l e . e u}$.

Looking further ahead, there are two events scheduled (relatively) near to one another in time and space next July. We are delighted to be able to give you early notice that for 2016 the IJCLE conference with the Association for Canadian Clinical Legal Education (ACCLE) Conference will be hosted by the University of Toronto. The conference, entitled The Risks and Rewards of Clinic encourages participants to reflect on the balance between risk and reward for all the stakeholders in clinic. In particular, we would like to encourage participants to include student and other partners' voices in their presentations, ideally through collaborative writing and presentation in person or through video calling or recordings. 


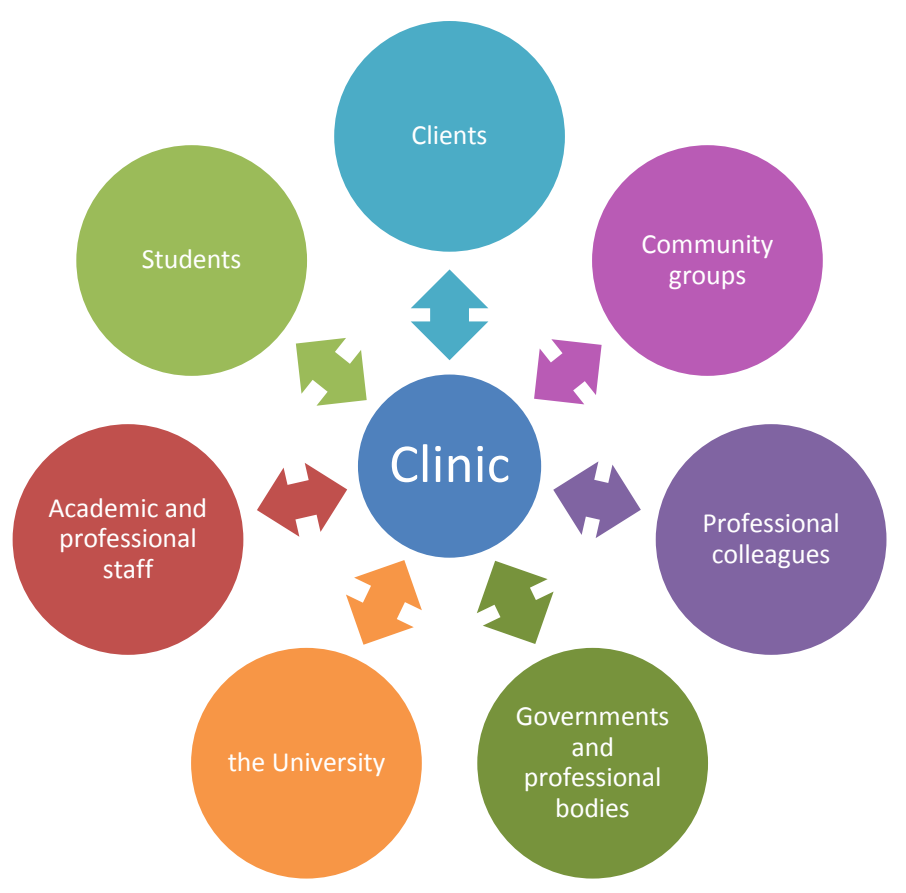

This will be followed by the International Legal Ethics Conference VII (ILEC VII), which Fordham Law School will host in New York City on July 14-16, 2016 focusing on legal education, ethics, technology, regulation, globalization and rule of law (www.law.fordham.edu/ilec2016). I hope many colleagues will be able to come to both events, since two papers for one lot of travel can be sold as good value to budget committees!

Please send me news of clinical events for our November edition as well as your papers from GAJE, IJCLE and ENCLE. Don't stick them in a drawer when you get home, get them on the map.

John Brehm, fragment from Getting Where We're Going, Poetry, January 2008 downloaded from http://www.poetryfoundation.org/poetrymagazine/poem/180547 